\title{
PELATIHAN MODEL PEMBELAJARAN PROBLEM BASED LEARNING SESUAI KURIKULUM 2013 PADA GURU DAN CALON GURU
}

\author{
EtinSolihatin $^{1)}$, AdiWijanarko ${ }^{2)}$ \\ etinsolihatin@yahoo.com \\ JurusanIlmuSosialPolitik, FakultasIlmuSosial, UniversitasNegeri Jakarta
}

\begin{abstract}
ABSTRAK
Setelah dilakukan kegiatan pelatihan model pembelajaran Problem Based Learning sesuai kurikulum 2013 merupakan sarana yang efektif dalam memberikan pencerahan, sekaligus melatih praktek pembelajaran. Disamping itu tugas Perguruan Tinggi untuk melaksanakan Tri Dharma yaitu pengabdian masyarakat dapat terelisasi dengan baik.
\end{abstract}

Kata Kunci :Pembelajaran, Problem Based Learning

\section{PENDAHULUAN}

\section{A. Analisis Situasi}

Program Studi PPKN, Jurusan Ilmu Sosial Politik, Fakultas Ilmu Sosial Universitas Negeri Jakarta mengemban amanah untuk merealisasikan Tri Dharma Perguruan Tinggi.Tri Dharma Perguruan Tinggi meliputi Pendidikan, Penelitian, dan Pengabdian Pada Masyarakat.

Salah satui mplentasinya adalah melakukan Pelatihan Model Pembelajaran Problem Based Learning bagi guru dan calon guru. Problem Based Learning menurut Renzulli, Gentry danRies (2003:53) "Problem Based Learning is typically done in small discussion groups, where students must engage in inquiry and the teacher's role become on of facilitator or resource guide". Dalam Kurikulum 2013 pendekatan dengan Scientific, dengan model pembelajaran Problem Based Learning, Project Learning, Discovery Learning, dan model lain yang relevan.

Namun sosialisasi pelaksanaan Kurikulum 2013 belum terlaksana dengan baik.Padahal Kurikulum 2013 harus sudah dilaksanakan mulai bulan Juli 2014.Sudah barang tentu banyak sekolahan yang belum siap melaksanakannya.Untuk itu kami dari Tim P2M Jurusan Ilmu Sosial Politik terpanggil untuk melaksanakan pengabdian kepada masyarakat, agar mereka memahaminya dengan baik.Jangan sampai secara teori harus melaksanakan Kurikulum 2013, namun kenyataannya menggunakan kurikulum yang lama.

Pada akhir kegiatandiharapkan guru dancalon guru memahiri model pembelajaran Problem Based Learning, yang sangat dianjurkan dalam Kurikulum 2013.Disamping itu dapat memperkaya khasanah ilmu pengetahuan khususnya model pembelajaran Problem Based Learning, sehingga pembelajaran PKn lebih menantang dan menarik. Dengan demikian tantangan masa kini dan masa yang akan datang dapat diatasi oleh peserta didik dengan baik, karena mereka berlatih terus memecahkan berbagai permasalahan yang ada dan mencari alternatif solusi yang baik.

Mengingat pentingnya kesadaran peningkatan skill tentang pembelajaran Problem Based Learning berbasis IPTEKS, maka kami berencana melakukan pelatihan model Pembelajaran Problem Based Learning dalam rangka mengaplikasikan kurikulum 2013 guna meningkatkan kemampuan guruguru dan calon guru dalam bidang pembelajaran. 


\section{B. TujuanKegiatan}

Kegiatan pengabdian masyarakat ini memiliki tujuan sebagai berikut:

1. Meningkatkan pengetahuan dan pemahaman bagi guru mengenai model pembelajaran problem based learning.

2. Meningkatkan kemampuan (skill) kualitas pembelajaran melalui pelatihan model pembelajaran problem based learning.

\section{Manfaat Kegiatan}

Adapun manfaat kegiatan yaitu :

1. Diharapkan agar guru-guru memiliki pengetahuan dan pemahaman tentang model pembelajaran problem based learning.

2. Adanya peningkatan kualitas pembelajaran, kemampuan (skill) dalam melaksanakan model pembelajaran problem based learning.

\section{KAJIAN TEORI}

\section{A. Problem Based Learning}

Problem based learning merupakan suatu pendekatan pembelajaran dengan menggunakan permasalahan dalam kehidupan nyata sebagai bahan untuk dipelajari dalam meningkatkan kemampuan berpikir peserta didik.

MenurutArends (2008:41) "Problem

based learning adalah model pembelajaran dengan pendekatan pembelajaran peserta didik masalah autentik, sehingga peserta didik dapat menyusun pengetahuannya sendiri, menumbuhkembangkan keterampilan yang lebih tinggi dan inkuiri, memandirikan peserta didik, dan meningkatkan kepercayaan diri sendiri".

\section{Model}

inibercirikanmenggunakanmasalahkehidupann yatasebagaisesuatu yang harus dipelajari peserta didik untuk melatih dan meningkatkan keterampilan berpikir kritis dan memecahkan masalah serta mendapatkan pengetahuan konsep penting.

Menurut Renzulli, Gentry danRies (2003:53) "Problem based learning is typically done in small discussion groups where students must engage in inquiry and the teacher's role become on of facilitator or resource guide".

JadimenurutRenzuli, Gentry dan Reis dalam problem based learning peserta didik dikelompokkan menjadi kelompok kecil untuk melakukan suatu diskusi berhubungan dengan penemuan yang akan dilakukan. Guru berperan sebagai penyaji masalah, membantu menemukan masalah dan memberi fasilitas penemuan, yang dapat meningkatkan pertumbuhan inkuiri.

\section{Tujuan Problem Based Learning}

Ada beberapa tujuan yang ingin dicapai dalam pelaksanaan problem based learning yaitu memudahkan tercapainya kompetensi untuk memperoleh pengetahuan baru, terampil berkomunikasi, kerjasamatim, pemecahan masalah, tanggungjawab untuk belajar mandiri, berbagi informasi dan menghargai orang lain.

Keterampilan dan sikap umum yang dihasilkan problem based learning menurut Wood (2003:328) BMJ volume 326, 8 Februari 2003 bmj.com yaitu :

- Teamwork

- Chairing a group

- Listening

- Recording

- Cooperation

- Respect for colleagues views

- Critical evaluation of literature

- Self directed learning and use of resources

- Presentation skills

\section{Langkah-langkahProblem \\ BasedLearning}

Problem based learning terdiri dari lima tahapan utama. Kelima tahapan itu 
dimulai dengan guru memperkenalkan peserta didik dengan suatu situasi masalah dan diakhiri dengan penyajian dan analisis hasil kerja peserta didik.

Tahapanproblem based learning menurutDepdiknas (2007:267):

\begin{tabular}{|l|l|}
\hline Tahapan PBL & $\begin{array}{l}\text { TahapanTingkahLaku } \\
\text { Guru }\end{array}$ \\
\hline $\begin{array}{l}\text { Tahap 1 } \\
\text { prientasi } \\
\text { kesertadidik }\end{array}$ & $\begin{array}{l}\text { Guru menjelaskan tujuan } \\
\text { pembelajaran, menjelaskan } \\
\text { logis yang dibutuhkan, } \\
\text { memotivasi peserta didik } \\
\text { agar terlibat pada } \\
\text { pemecahan masalah yang } \\
\text { dipilihnya. }\end{array}$ \\
\hline $\begin{array}{l}\text { Tahap 2 } \\
\text { Mengorganisasipe } \\
\text { sertadidik untuk } \\
\text { belajar }\end{array}$ & $\begin{array}{l}\text { Guru membantu peserta } \\
\text { didik mendefinisi-kan dan } \\
\text { mengorganisasikan tugas } \\
\text { belajar yang berhubungan } \\
\text { dengan masalah tersebut }\end{array}$ \\
\hline $\begin{array}{l}\text { Tahap 3 } \\
\text { Membimbing } \\
\text { penyelidikan } \\
\text { individual dan } \\
\text { kelompok }\end{array}$ & $\begin{array}{l}\text { Guru mendorong peserta } \\
\text { didik untuk mengumpul- } \\
\text { kan informasi yang sesuai, } \\
\text { melaksanak aneksperimen } \\
\text { masalah } \\
\text { untuk mendapatkan } \\
\text { penjelasan dan pemecahan } \\
\text { masalahnya. }\end{array}$ \\
\hline hasil karya
\end{tabular}

\section{Keuntungan dan Keterbatasan Problem Based Learning}

Keuntungan dan keterbatasan problem

based learning menurut Akinoglu $\mathrm{O}$ dan Tandogen R.O. (2007: 71-81) dalam"The

Effects of Problem Based Active Learning in Science Education on Students' Academic Achievement, Attitude and Concept Learning”, Eurasia Journal of Mathematics, Science \& Technology Education, 3, (1), 71-81.

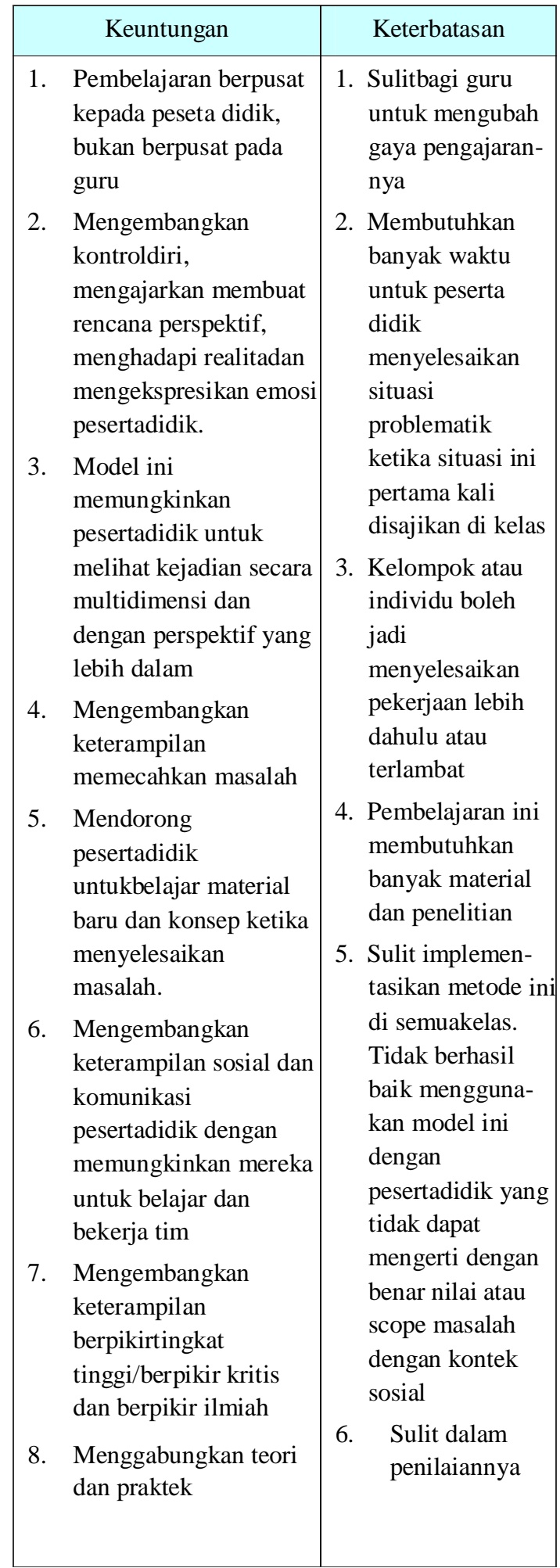




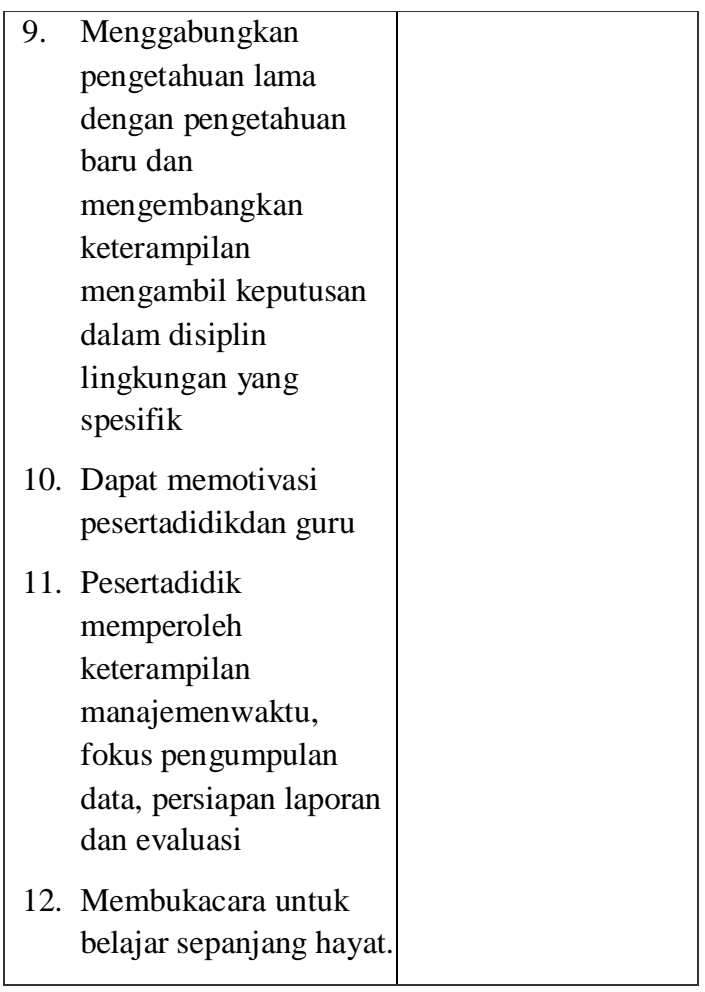

\section{METODE PELAKSANAAN}

\section{A. Metode Pemecahan Masalah}

Untuk mensukseskan program pelatihan model pembelajaran problem based learning adalah melalui tahapan : Memberikan informasi penting berkaitan dengan problem based learning denganP ower Point. Praktek pelaksanaan dilakukan oleh guru-guru dan calon guru (sebagai peserta pelatihan) Tanya jawab untuk lebih memantapkan hal-hal yang berkaitan dengan model pembelajaran problem based learning

\section{B. Khalayak Sasaran}

Khalayak sasaran yang dianggap strategis (yang mau dan mampu) untuk dilibatkan dalam pelatihan model pembelajaran problem based learning, yaitu guru-guru dan calon guru di Desa Cibadak, Kabupaten Bogor.

\section{Tempat dan Waktu Kegiatan}

$$
\text { Kegiatan pelatihan model }
$$

pembelajaran problem based learning bagi guru-guru di ruang kelas SD Huntara Desa Cibadak, Kecamatan Bogor. Waktu kegiatan dilaksanakan setelah proposal ini disetujui.

\section{PELAKSANAAN KEGIATAN}

\section{A. Realisasi Pemecahan Masalah}

Berdasarkan kerangka masalah sebagaimana diuraikan di atas, maka langkah pemecahan masalah dilaksanakan sebagai berikut:

1. Mengadakan koordinasi dengan pihakpihak terkait :

a. Mengurus perizinan tempat

b. Narasumber materi Model Pembelajaran Problem Based Learning sesuai Kurikulum 2013 pada guru dan calon guru, dari Tim Pengabdian Masyarakat.

2. Menyusun agenda atau susunan acara.

\section{B. Sasaran}

Peserta yang mengikuti pelatihan model pembelajaran Problem Based Learning bagi guru dan calon guru sebanyak 20 orang di desa Cibadak.

\section{Metode}

Untuk mensukseskan program pelatihan ini, metode yang digunakan adalah partisipasi aktif dengan melalui tahapan: (1) ceramah, metode ini penting untuk menyampaikan informasi penting berkaitan dengan "Model Pembelajaran Problem Based Learning Sesuai Kurikulum 2013", disertai print out bahan tayangan (power point). (2) tanya jawab yang dilaksanakan secara aktif oleh seluruh peserta. (3) praktek pembelajaran dengan Model Problem Based Learning”.

\section{HASIL KEGIATAN}

A. Hasil Kegiatan

Hasil kegiatan "Pelatihan Model Pembelajaran Problem Based Learning sesuai Kurikulum 2013", di desa Cibadak diantaranya: 
1. Meningkatkan pengetahuan peserta tentang "Model Pembelajaran Problem Based Learning Sesuai Kurikulum 2013, yang dapat melatih peserta didik untuk memecahkan masalah dalam kehidupan sehari-hari.

2. Terjadinya sikap positif dan semangat mengajar lagi meskipun pernah kena bencana longsor, dan beberapa guru tinggal di Huntara (Hunian Sementara).

\section{B. Hasil Evaluasi}

Evaluasi dilakukan terhadap contoh praktek "Problem Based Learning". Di samping itu minat dan antusias peserta agar pengabdian masyarakat terus dilaksanakan di daerahnya.

\section{KESIMPULAN}

Setelah dilakukan kegiatan pelatihan pada pengabdian masyarakat ini, dapat disimpulkan bahwa : pelatihan Model Pembelajaran Problem Based Learning Sesuai Kurikulum 2013, merupakan sarana yang efektif untuk memberikan pencerahan, sekaligus melatih praktek pembelajaran. Di samping itu tugas Perguruan Tinggi untuk melaksanakan Tri Dharma, dapat terealisasi dengan baik.

\section{DAFTAR PUSAKA}

Amir, MT. 2009. Inovasi Pendidikan Melalui Problem Based Learning. Bagaimana Pendidikan Memberdayakan Pemelajar di Era Pengetahuan, Jakarta: Kencana Prenada Media group.

Izhak, Hasoubah Z. 2004. Developing Creative and Critical Thinking Skill (Cara Berpikir Kreatif dan Kritis), Bandung: Yayasan Nuansa Cendekia.

Lepinski, C. 2005. Problem Based Learning: A New Approach to Teaching Training \& Developing Employees, San Rafael CA: Merin Country Sheriff's Office.

Sevin, et. al. 2000. Foundation of Problem Based Learning. SRHE and Open University Press Imprint. General Editor Heather Eggins.

\section{Sumber Internet:}

Hmelo-Silver,CE.2004. Problem Based Learning: What and How Do Student Learn? (on line) Education Psychology Review, vol. 16, 236-266. Tersedia di http://kanagowa.iti.cs.cmu.dey (15 September 2010). 